This item was submitted to Loughborough's Research Repository by the author.

Items in Figshare are protected by copyright, with all rights reserved, unless otherwise indicated.

\title{
Sticky prices or economically-linked economies: the case of forecasting the Chinese Stock Market
}

PLEASE CITE THE PUBLISHED VERSION

http://dx.doi.org/10.1016/j.jimonfin.2013.11.001

\section{PUBLISHER}

(c) Elsevier Ltd

VERSION

SMUR (Submitted Manuscript Under Review)

\section{PUBLISHER STATEMENT}

This work is made available according to the conditions of the Creative Commons Attribution-NonCommercialNoDerivatives 4.0 International (CC BY-NC-ND 4.0) licence. Full details of this licence are available at: https://creativecommons.org/licenses/by-nc-nd/4.0/

\section{LICENCE}

CC BY-NC-ND 4.0

\section{REPOSITORY RECORD}

Jordan, Steven J., Andrew J. Vivian, and Mark E. Wohar. 2019. "Sticky Prices or Economically-linked Economies: The Case of Forecasting the Chinese Stock Market". figshare. https://hdl.handle.net/2134/24289. 


\title{
Sticky Prices or Economically-Linked Economies: The case of Forecasting the Chinese Stock Market
}

\begin{abstract}
We explore whether economic links via trade affect aggregate Chinese stock market returns. We find that market return indices from countries that China net imports from can forecast the Chinese aggregate market return at the weekly time horizon. The stock returns of countries that China net exports to have no consistently significant OOS predictability.

The economic intuition for our results follows from the fact that China has positioned itself as a low-cost provider competing on price. As a low-cost provider China has a more difficult time passing cost increases through to export customers because of sticky prices. However, import costs, e.g., raw materials, are subject to both consumption and speculative demand and thus vary. We can conclude that costs will drive short term economic gains for the overall Chinese economy. One interpretation of our results is that supply shocks are absorbed within 2 weeks.
\end{abstract}

\section{Introduction}

Can aggregate Chinese stock returns be forecast? To date, there is mixed US evidence on out-of-sample (OOS) predictability using fundamentals and macro variables, the two work horses of the predictability literature. However, outside the US there is mounting evidence that markets are predictable by alternative variables. ${ }^{1}$ This paper adds to the international predictability literature by exploring whether economic links between countries are useful for identifying predictor variables for the Chinese market. Chan, Fung, and Thapa (2007) provide a recent survey of financial research on China. ${ }^{2}$ They discuss several crosssectional predictability studies but virtually nothing on aggregate market OOS predictability. ${ }^{3}$ Two recent studies explicitly consider OOS forecasts of the Chinese market. Rapach et al., (2011) study the forecast power of Chinese fundamentals and Goh, Jiang, Tu, and Wang (2013) study the forecast power of both

\footnotetext{
${ }^{1}$ See Jordan, Vivian, and Wohar (2012) and Lee and Rui (2000) for a review of the international fundamental predictability literature.

${ }^{2}$ Some papers examine the relation between China and other aggregate markets. However, these papers focus on the Greater China markets or a sample of Asian countries, sometimes including the US. Hsiao, Ching, and Wan (2012) explore the impact on 24 countries from the economic integration of Hong Kong with mainland China. The focus in this literature is on contagion or other market linkage characteristics. A significant difference between this line of literature and our paper is that this line of literature does not explore out-of-sample forecasting.

${ }^{3}$ We explore the predictability of the aggregate Chinese market. However, there are two papers that explore predictability of cross-sectional differences. First, Wang and Xu (2004) apply a three-factor model to A-shares in the Chinese stock market using data from July 1996-June 2002. They find that size is able to explain the cross-sectional differences. Contrary to the findings using US data, the beta and book-to-market ratio did not account for return differences across individual stocks. Second, Chen, Kim, Yao, and Yu (2010) consider 18 firm-specific variables that have been show to predict cross-sectional stock returns in the US, and examine their relation to stock returns (at the annual horizon) in China over the period 1995-2007. They find that only 5 of the 18 variables predict Chinese stock returns. The explanation for this finding of weak predictability that they find support for is that, i) return predictors in China are less heterogeneously distributed than they are in the US and ii) stock prices in China are less informative in China than they are in the US, in the sense that there are persistent noisy valuations and persistent mispricing in China.
} 
Chinese and US fundamentals. These studies provide some initial evidence that the Chinese equity market index has a predictable component. In contrast to these studies we i) examine other countries' returns as predictors, ii) examine weekly frequency data and iii) focus on China's major trading partners. According to The Economist (2011) China could surpass the US as the number one economy by 2020. Thus, China is growing in importance in terms of world trade. ${ }^{4}$ Thus, understanding whether China is substantially different from other large economies ${ }^{5}$ and whether the returns of trade partner economies are useful in forecasting the aggregate Chinese stock market return index is of vital importance. The purpose of this paper is to fill this gap and investigate whether trade relations impact out-of-sample (OOS) predictability of Chinese stock market returns. ${ }^{6}$

There are two potential theories that might motivate superior OOS predictability to one subset of countries over another. China has positioned itself as an export economy. ${ }^{7}$ Being an export oriented manufacturing economy has important implications, foremost is that China will compete on price. China exports a lot of manufactured goods, whose prices are sticky since contracts are previously agreed; therefore, export prices cannot respond quickly to economic fluctuations. Hence net export countries returns will not impact Chinese returns in the short-run. On the other hand, China is a major importer of raw materials, whose prices are determined daily on the global market; therefore raw material costs are flexible in the short term. Hence, shocks to Chinese firm's costs will affect its profits (since export prices are sticky) in the short-run and thus affect equity market returns. Hence net import countries returns will impact Chinese returns in the short-run. This sticky-price theory suggests that countries for which China is a net exporter should not forecast the performance of the aggregate Chinese market. However, China's cost are linked to those countries for which China is a net importer. That is, raw materials, such as commodities, are subject to speculative

\footnotetext{
${ }^{4}$ The growing importance of China is reflected in the increase in the number of articles with a China focus. For example, Sheng (2013) studies China reserve diversification strategy, an important global driver. A search of Web of Knowledge clearly demonstrates the growth in research focusing on China. In 1990, 2000, and 2012 there were just under 140, 420, and 2550 articles, respectively, in the Business and Economics section with the search term "Chin*".

${ }^{5}$ China is an interesting new market structure that may differ significantly from the standard free-market paradigm. According to the U.S.-China Economic and Security Review Commission (see Szamosszegi and Cole, 2011), the Chinese government held a controlling interest in over 70\% percent of firms listed on the Chinese markets. Another important difference between China and the West is that the major banks in China are owned by the Chinese government, so low interest loans to its own firms may provide competitive advantages.

${ }^{6}$ We focus on Chinese 'A' shares which comprise of $99 \%$ of all trading volume in China.

${ }^{7}$ China has historically positioned itself as a low-price exporter, however, this has changed in the most recent years. Research has documented that a low cost strategy works and remains viable in China. For example, Aulakh, Kotabe, and Teegen (2000) study export strategies of emerging market firms exporting to developed markets and find that cost-based strategies enhance export performance. Li, Zhou, and Shao (2009) find that low-cost positions remain a profitable strategy for Chinese firms competing in the export market .
} 
demand in addition to demand for production, which will induce short-term variation in China's import prices. Thus, the sticky-price theory also suggests that these net import countries should have short term OOS predictability for China. An alternative to the sticky-price theory is the economically-linked countries theory. This is a macro extension of the results in Cohen and Frazzini (2008) that consumer firms have predictive power for supplier firms. In our context, this would imply that China's net export countries (China's customers) should forecast the aggregate Chinese market. For net exporters, the economically-linked theory makes predictions that are diametrically opposite to those made under the sticky-price theory. We conduct tests in order to differentiate between these two competing theories. ${ }^{8}$

Overall, we find clear evidence of OOS predictability of the Chinese equity market return at short horizons for countries for which China is a net importer. The significance is both statistically and economically significant. Not only can forecast accuracy be improved by a statistically significant margin, but investor welfare can be enhanced via a portfolio allocation strategy. Given that ETFs on China's A shares are now available, market timing strategies could be implemented for China by all investors, not just Chinese nationals. We also find that the sticky-price theory is better at predicting the dynamic relationship between China and its net import/export trade partners. Finally, although it has been extensively documented that combination of forecasts outperform single model predictions, we document that a novel finding in that combining across just a subset of predictors performs better than combining across all predictors. Using our insight, we suggest a new technique in order to enhance forecast gains from combination forecast methods.

\section{Hypothesis Development}

China has received very little attention until recently in the OOS aggregate stock return forecasting literature. ${ }^{9}$ For eleven industrialized countries, Rapach, Strauss, and Zhou (2011) show that the US aggregate market return has predictive power to forecast 11 developed market returns. Though China is classified as a developing country, it is a growing industrial force. It currently ranks as the number two economy by GDP and is projected to overtake the US as number one within a few decades (The Economist, 2011). The US is also China's largest trading partner. Thus, our first hypothesis extends Rapach et al.'s work:

\footnotetext{
${ }^{8}$ Cohen and Frazzini (2008) study the consumer effect on supplier. There may also be a supplier effect on the consumer that can be a result of an economically-linked theory. However, we focus on the different predictions for net exporters since this allows us to differentiate between these theories.

${ }^{9}$ Rapach et al., 2011 and Goh et al., 2013 are notable exceptions.
} 
Hypothesis 1: As a growing industrial nation, the Chinese stock market return is forecastable by the US market return.

We have two competing theoretical arguments to support the development of our second hypothesis. The first is a macro argument. Unlike many industrialized nations, China is a low-cost producer. What this means is that China has positioned itself in the world market as a country that looks for volume by competing on price. This is evident by the fact that China net exports to 329\% more countries than it net imports. ${ }^{10}$ Given that China competes on price, short term, its revenues will be sticky. This is due to the fact that contracts are typically agreed in advance of delivery and shutting facilities down is typically not an option, at least in the short term. Thus, import cost shocks cannot be passed through to export prices. Therefore, import cost shocks, which can be driven by global commodity markets, must be absorbed by Chinese manufacturers. We thus stipulate our second hypothesis:

Hypothesis 2A: As revenues are sticky, countries for which China is a net exporter should not have short term OOS predictability on China's aggregate market. However, given cost shocks are absorbed immediately, countries for which China is a net importer should exhibit OOS predictability for China's market return.

Corollary 2A: Since China is extremely dependent on commodity imports, commodity rich nations should exhibit stronger OOS predictability for China's market return.

Our second argument is based on micro evidence. Cohen and Frazzini (2008) demonstrate that economicallylinked firms can convey information about their respective return performance. Using a customer database, they demonstrate that information shocks to the customer provide economically significant predictability for the seller. This hypothesis suggests countries that China is a net exporter to should have larger predictability. This is thus a test of whether Cohen and Frazzini's empirical evidence extends to a macro level. We can now state our alternate second hypothesis:

Hypothesis 2B: As customer nations convey economically significant information concerning their main seller countries, countries for which China is a net exporter should have short term OOS predictability on China's aggregate market.

\footnotetext{
${ }^{10}$ http://www.njcdtjx.com/upload/yearbooks/yearbook_2010/html/R0607e.htm contains data on China's trade partners.
} 
Since Hypothesis 2B, which is based on the economically-linked countries theory, predicts exactly the opposite effect for China net exporters than Hypothesis 2A, which is based on the sticky price theory, we can make a clean test between these two theoretical motivations by examining the OOS predictability of countries that China net exports to. It should be noted that even though China is one of the largest economies, its size is not an important attribute for us to distinguish between our competing hypotheses.

\section{Data}

Our sample covers China A share index $(\mathrm{CH})$ and China's 15 largest trading partners, including: India (IN), Japan (JP), Korea (KO), Malaysia (MY), Singapore (SG), Thailand (TH), the United Kingdom (UK), and the United States (US). Russia and Hong Kong are excluded. ${ }^{11}$ This results in a final sample of 13 predictor markets. Our data represents a balanced sample period of 1995-2011. The data is primarily from Thomson Datastream. We collect weekly data from January 1995 to December 2011. We use mid-week to mid-week returns in order to control for potential weekend effects. Returns from China and all markets closing before the Chinese stock market close (i.e., AU, JP, KO, and TW) are calculated Wednesday-to-Wednesday. To ensure that predictor returns are available before China's market close and to prevent a look-ahead bias, we use Tuesday-to-Tuesday returns for all other countries. We use 156 weeks prior to January 2005 as a training period for our OOS model, ${ }^{12}$ thus our final predictions are made from January 2005 to December 2011. This leads to 365 one-week horizon, 364 two-week horizon, and 362 four-week horizon forecasts.

Table I provides a summary of descriptive statistics for aggregate market returns for our sample of countries. We report the mean, the standard deviation, the minimum, and the maximum for China and for each predictor country used. The average nominal returns (RET) vary substantially across countries from $-0.0005(-0.05 \%$ per week or $-2.6 \%$ per year compounded) in Japan, up to 0.0030 (1.2\% per month or $16.9 \%$ per year compounded) in Brazil. The standard deviation of returns also varies substantially across countries from 0.0411 for India down to 0.0208 for Australia.

\section{[Table I about here.]}

Table II provides the contemporaneous correlation matrix for aggregate market returns for China and

\footnotetext{
${ }^{11}$ Data on Russia is not available until 1998. Hong Kong is excluded because of cross-listing of Chinese firms in Hong Kong.

${ }^{12}$ The 366 weeks from January 1995 to January 2002 is the in-sample period.
} 
each of the 13 predictor nations. Several of the correlations across markets is large, exceeding 0.800 between the UK and NL. The correlations exceed 0.500 in over $25 \%$ of the country pairs. Almost all countries, with the exception of China, has large correlation with the US. Every country, with the exception of China, has at least one correlation of at least 0.456 . In stark contrast, China's largest correlation is 0.171 with India. Chinese market returns are clearly different than the "average" market return. ${ }^{13}$ We use this insight to look at combination forecasts as correlation coefficients below one suggest there could be benefits from combining forecasts.

\section{[Table II about here.]}

\section{Methodology}

In this section we review the methodologies used in the paper. We utilize individual predictor models, combination models, and utility-based models.

\subsection{Individual Predictor Models}

To assess the impact of individual variables, the Autoregressive Distributive Lagged (ARDL) model is used to estimate the linkage between the dependent, lagged dependent, and a potential predictor variable (including its lags). These ARDL models take the form of (1) below. ${ }^{14}$

$$
y_{t+h}^{t}=\alpha+\sum_{j=0}^{q_{1}-1} \beta_{j} y_{t-j}+\sum_{j=0}^{q_{1}-1} \lambda_{j} x_{i, t-j}+\epsilon_{t+h}^{h}
$$

An expanding (or recursive) window is used to make the $h$-step ahead forecast. $y_{t+h}^{t}$ is the h-step ahead Chinese market return. $x_{i, t-j}$ is the $i^{t h}$-country's market return at time $t-j$. The ARDL model controls for past changes in the dependent variable and allows for $q_{1}$ lags, up to a maximum four, of the independent variable. The $\mathrm{AR}(\mathrm{p})$ benchmark is nested in the ARDL model by restricting $\lambda_{j}$ to be 0 for all $j$. The ARDL results are compared to an $\mathrm{AR}(\mathrm{p})$ model for Chinese returns. Schwarz Information Criteria (SIC) is used to

\footnotetext{
${ }^{13}$ Although we cannot test the reasons for why China differs in correlation with other markets, lower correlations for China might reflect institutional setting, e.g., A shares not open to international investors.

${ }^{14}$ We tested for cointegration between the Chinese market price and each of the 13 potential explanatory market prices. In 12 of 13 tests, the error term was nonstationary indicating no cointegration relationship. Thus, our first differenced or return-based ARDL model is correctly specified.
} 
determine the number of lags.

\subsection{Combination Predictor Models}

It is now a well documented empirical fact that combining forecasts generally improves OOS predictability of aggregate financial and economic variables. We discuss each method intuitively and refer the reader to Rapach, Strauss, and Zhou (2010) for details. We use three simple combination strategies: Mean, Median, and the Trimmed mean, where the trim excludes the lowest and highest forecasts from the average. In addition, we use two discount forecast combination models. By decreasing the discount rate, more recent observations can be weighted more heavily. As in Stock and Watson (2004), we use $\delta=1.0$ (no discounting of past forecasts) and $\delta=0.9$ (more weight on most recent forecasts) resulting in Stock and Watson's discounted mean-square forecast error (DMSFE) methods DMSFE(1) and DMSFE(0.9). Finally, we use cluster combinations to control for forecast persistence (see Aiolfi and Timmermann, 2006). Utilizing a hold-out period, the individual ARDL models are ranked by their mean square forecast error (MSFE) and clusters are created by consecutively adding the next lowest MSFE ARDL model to the cluster. Clusters are formed on the MSFE over a rolling window. Within the cluster with previous best (PB) MSFE an average of ARDL model forecasts are taken to generate the cluster combination forecast. We utilize this method with two clusters $[\mathrm{C}(2, \mathrm{~PB})]$ and three clusters $[\mathrm{C}(3, \mathrm{~PB})] .{ }^{15}$

\subsection{Forecasting Tests}

Forecast encompassing tests compare the information content of two models. A linear combination of each forecast is constructed where the weights sum to one. The null is that the weight on the model under consideration is zero. If the null is rejected, then the model under consideration contains information orthogonal to that in the base model. Harvey, Leybourne, and Newbold (1998) provide the MHLN test statistic. We also use the Clark and West (2007) CW test, which tests for equal forecast accuracy and is distributed as a standard normal.

\footnotetext{
${ }^{15} \mathrm{C}(\mathrm{P}, \mathrm{PB})$ uses $\mathrm{P}$ clusters. PB denotes that we employ the Previous Best conditional combination strategy
} 


\subsection{Economic Value Tests}

We follow Campbell and Viciera (2002) and Campbell and Thompson (2008) to measure the gain from market timing of a mean-variance optimizing investor. We use log returns, rather than simple returns, and we calculate volatility using a 52-week rolling window. Gain is the utility increase from market timing measured as the excess return over the benchmark model, which is then penalized for the excess volatility over the benchmark model. We also implement the GISW manipulation proof method of Goetzmann, Ingersoll, Speigel, and Welch (2007). The GISW method measures the certainty equivalent gain (it is basically the alpha generated by the model).

\subsection{Robustness - Persistent Predictor, Heteroscedasticity, and Endogeneity}

Within the return prediction literature often the predictors (e.g. dividend-price ratio, price-earnings ratio, dividend-payout, and book-to-market) can be quite persistent and also correlated with the disturbance term. Stambaugh (1999) has shown that the combination of persistent predictors and endogeneity results in smallsample bias of the OLS estimator. Another problem that often plagues predictive regressions is that returns may be heteroscedastic and volatile, dwarfing the signal of the predictor, making it difficult to detect predictability.

Westerlund and Narayan (2012) investigate the performance of three estimators applied to US time series data over the period 1871-2008, looking at excess returns, dividend-yield, the earnings-price ratio, and the dividend-payout ratio. The three estimators applied to the above data are; i) OLS, ii) the bias-adjusted OLS estimator of Lewellen (2004) and iii) the feasible GLS estimator of Westerlund and Narayan (2011).

The FGLS estimator is the most general and accounts for persistence, heteroscedasticity, and endogeneity. The adjusted-OLS estimator accounts for persistence and endogeneity, but not heteroscedasticity. The OLS estimator does not account for any of the three issues.

Westerlund and Narayan (2012) find that the FGLS estimator generally performs best. In order to quantify the economic significance of the results from the forecasting comparison, they examine whether a mean-variance investor would be better off in terms of utility using the FGLS estimator rather than the adjusted-OLS estimator. They find that the FGLS yields higher utility.

As a robustness check, we conduct our prediction exercises using the FGLS estimator. Given that our 
predictors are returns and hence are not persistent, it is unlikely that the FGLS estimator will outperform the OLS estimator. However, heteroscedasticity may be a concern and hence we also employ the FGLS estimator.

\section{Empirical Results}

In this section we conduct several OOS forecast tests for China's stock market. We conduct individual ARDL tests for China's largest trade partners. We then conduct tests based on combination models. Given the conflicting predictions on exporter versus importer OOS predictability, we split the data according to this dimension in order to discern between the two theoretical motivations. We perform encompassing tests to examine which countries returns provide new information. We end by examining the economic benefits from portfolio allocation based on forecasts.

\subsection{Individual ARDL OOS Forecasts}

Table III shows various forecast results for individual country predictors using an ARDL model. Forecasts are shown for 1-week, 2-week, and 4-week forecast horizons. The most notable result in the individual country ARDL results is that there is no OOS predictability beyond 1 week. At the 4-week horizon, Australia's market return forecasts China's market return with a mean squared forecast error of 0.999 relative to the benchmark; this indicates that including lagged Australian returns only reduces forecast error by $0.001 \%$. This is statistically insignificant from zero, i.e., the p-value of the $\mathrm{CW}$ test (referred to as $\mathrm{p}(\mathrm{CW})$ ) is 0.28 . The 2- and 4-week forecast horizons are all insignificant. However, at the 1-week forecast horizon China's market return can be forecast. Several countries have significant OOS predictability. Australia, Brazil, and Malaysia all outperform the AR(p) benchmark at the 5\% significance level (significance is given in the $\mathrm{p}(\mathrm{CW})$ column). In addition, there is weak outperformance at the $10 \%$ level by Germany, Taiwan, and the US. The fact that the US only predicts China at the $10 \%$ level provides weak support for Hypothesis 1 . These results also provide a rough measure for the time lag for China's aggregate market to adjust to supply shocks. Such supply shocks are incorporated within a two week period.

[Table III about here.] 
The second most notable result in Table III is that almost all the OOS predictability comes from countries for which China is a net importer. Column Im/Ex indicates if China has a net import trade (I) or a net export trade (E) with each country. Five of the six significant predictors are net import countries. All three countries that beat the $\mathrm{AR}(\mathrm{p})$ benchmark at the standard 5\% significance level are net import countries. This result provides support for Hypothesis 2A, i.e., China has positioned itself as an export-oriented manufacturer. Prices are set in contracts before delivery and input prices may vary with market forces. Thus, China's economy is subject to sticky prices and is sensitive to supply shocks.

\subsection{Combination OOS Forecasts}

This section contains the forecast results from the forecast combinations. Table IV, Panel A reports results for the combination of all predictor countries at the 1-, 2-, and 4-week forecast horizons. Again, we find no significant OOS predictability at the 2- and 4-week forecast horizons. Given that forecast combinations have been shown to have much better forecasting accuracy (see Rapach et al., 2010), this result further strengthens the result that supply shocks are absorbed fully by two weeks. OOS predictability at the 1-week horizon is small across all methods; the reductions in forecast accuracy provided by combinations are never more than $1 \%$ of the benchmark forecast error. Although all combination models beat the AR(p) benchmark, outperformance is weak and only significant at the $10 \%$ level.

\section{[Table IV about here.]}

Next, we separate the universe of predictors into two groups: countries for which China is a net exporter and countries for which China is a net importer. The main intuition for separating the universe of stocks by net trade balance is provided by two competing theories: sticky export prices and economically-linked countries. Since these competing theories make opposite predictions on OOS predictability, we can use our combination tests as a robustness test to distinguish between theories. Panel B gives the results for net export countries. Not one combination model statistically outperforms the AR(p) benchmark at the 5\% level. These results do not agree with a growing literature that consistently finds outperformance by combination methods. The answer is provided in Panel C, which gives results for net import countries. Every combination model outperforms the benchmark. All but two, Median and Trimmed Mean, outperform at the 5\% significance level. These results are in stark contrast to the export results in Panel B and provide 
strong support for the commodity nature of China's economy and thus support Hypothesis 2A.

One last point should be made on the contrasting results in Panel B and C. Jordan and Vivian (2012) demonstrate that fundamentals generally do not forecast industrial country returns outside the large economies of the US and UK. They point out that a possible explanation is noise. Our results in Table IV provide direct evidence in favor of this noise explanation. The export countries do not forecast in single predictor forecasts. Thus, adding these to combination forecasts introduces noise into the forecast average. When these "noise" countries are removed and import countries are used alone to form forecast combinations, the significance of the outperformance increases sharply.

\subsection{Encompassing Test}

Next we consider encompassing tests. Encompassing tests examine if adding another forecast to a base forecast adds new information. Table $\mathrm{V}$ provides results for forecasting encompassing tests between two different predictor country forecasts. Overall the results are supportive of our earlier findings. We are testing if the forecast of the country at top of the column has a weight of zero when added to the forecast of the country at the left of the row. For example for Australia (Column) and India (Row), the p-value of 0.04 indicates that we can reject the null hypothesis that the forecast based on Australia has a weight of zero when combined with the forecast based on India. Thus, the Australian forecast is not encompassed by the Indian forecast, i.e. the Australian forecast adds new information over and above that contained in the Indian forecast. When we look at each column, the main countries that add new information over other predictor countries are the net import countries. For example, Australia, Brazil, Germany, Malaysia, and Taiwan again add information at the 5\% level. The statistical significance (at the 5\% level) is for net import countries in 20 out of 22 cases. Only two export countries reach the 5\% level for new information: Singapore and the United States. It is notable though that these countries only add information incrementally to Thailand, a country that does not perform well in these information tests. ${ }^{16}$

\section{[Table V about here.]}

\footnotetext{
${ }^{16}$ The limited rejection of forecast encompassing also offers a clue as to why combinations don't do better. Few countries add incrementally new info, so it is difficult for combinations to beat the best individual forecasts.
} 


\subsection{Portfolio Allocation}

We allow a mean-variance investor to time the market. Timing is accomplished by varying the weight on the investment in the Chinese stock market as the expected market risk premium varies. The investment weight is determined by mean-variance optimizing theory under the constraint that the weight in the Chinese equity market is restricted to be between 0 and 1.5 . This gives a direct measure of the economic value to forecasting. Table VI, Panel A gives the results for the individual country ARDL forecasts. Countries are separated into import and export groups. Overall, we find that there is economic value to forecasting. ${ }^{17}$ The economic value tests suggest the magnitude of forecasting gains are greater than those from the forecast accuracy tests in section 4.2. There is evidence of forecast value in both the import and export groups.

\section{[Table VI about here.]}

Panel B provides the forecast combination economic value results. Results are given for three groups: all, import, and export countries. OOS predictability is realized across the three groups (ALL, IMPORTERS, EXPORTERS) and for all combination methods. Again, the economic value tests provide stronger support than the statistical tests. The relative values between the ALL, IMPORTERS, and EXPORTERS sections are again of acute interest. When separated into import and export groups, the export combination forecasts generally underperform all country combination forecasts, and sometimes by a large amount (e.g., for C(3,PB) the gains drop from 8.98 in the ALL section to 6.60 in the EXPORTERS section). Again, in stark contrast, the IMPORTERS group attains higher economic value over the ALL group in five of seven strategies. Even though the magnitude of outperformance is generally stronger compared to forecast accuracy tests in section 4.2, the conclusion about whether to include low predictor countries into combination models is the same. Adding weak predictors, i.e., net exporters, increases noise and attenuates potential gains from combining methods.

\section{Robustness Tests}

In this section we conduct several robustness tests for our OOS forecast results. A recent econometric method has been proposed by Westerlund and Narayan (2012, hereafter WN). The WN feasible generalized

\footnotetext{
${ }^{17}$ Our reported utility gains are smaller than realized gains, as the penalty implied by setting risk aversion to three is higher than the ex-post data for our OOS period suggests.
} 
least squares (FGLS) model accounts for the issues of heteroscedasticity, predictor endogeneity, and persistence. Thus it might improve forecast accuracy. ${ }^{18}$ We thus control for these three potential econometric problems and rerun our tests using the WN-FGLS method. Another potential issue is that China became a member of the WTO on December 11, 2001. This may be an economically important result that could have linked China's economy more closely to other large economies. Goh et al. (2013) also find evidence of predictability after China entered the WTO, but not before. We control for this possibility by rerunning our tests with pre-WTO data. If our results hold pre-WTO, then the event of China's admission to the WTO is not driving our results.

\subsection{Robustness - Individual ARDL OOS Forecasts}

Table VII shows various forecast results for individual country predictors using the WN-FGLS rather than the ARDL model. Given predictability exists at the 1-week forecast horizon, we concentrate on forecasts at this time interval. Panel A provides robustness results using the full data sample. At the 1-week forecast horizon and 5\% significance level, China's market return can be forecast (i.e., the model outperforms an $\mathrm{AR}(\mathrm{p})$ benchmark) by only two countries: Australia and Malaysia. China is a net importer for both of these countries. Again, US index returns cannot predict the Chinese index returns.

\section{[Table VII about here.]}

Also in Panel A, we report utility gain tests (Utilility Gain column) and manipulation proof utility gain tests (GISW column). These tests again use the WN-FGLS model. We find utility gains can be made with individual predictor models for Australia, Malaysia, and Singapore. Results are slightly stronger for the manipulation proof method. If the US market was used, as suggested by prior literature, then there would have been large utility loss from using this model. Overall, our main findings from the single variate predictor models hold even after heteroscedasticity, predictor endogeneity, and persistence have been explicitly controlled.

\footnotetext{
${ }^{18}$ We also conducted our tests using the Lewellen (2004) estimator, which accounts for predictor endogeneity and persistence but not heteroscedasticity; these results were also qualitatively very similar to OLS (and WN-FGLS). Both, for the WN-FGLS and for the Lewellen method, the persistence was set to 0.05 , given the independent variable is a stock return, which is not persistent. However, our results are not very sensitive to the level of persistence; generally the closer persistence is to 0 the more similar the results to OLS. When estimating either the WN-FGLS or the Lewellen method, we only consider one lag of the independent variable in the ARDL model.
} 
Panel B presents the pre-WTO sample results. China joining the WTO on November 11, 2001 was a major economic event and could potentially have changed the dynamics between the Chinese aggregate market and other world aggregate markets. To control for this, we investigate if our results hold prior to China joining the WTO. Using individual predictor models suggests that there was no ability to forecast prior to China joining the WTO (consistent with Goh et al., 2013). We must caution that our sample period is very small (1999:01 to 2001:52), so there may not be enough data to measure the relationship, i.e., the signal-to-noise ratio may be too small. We revisit this question in the next subsection.

\subsection{Robustness - Combination OOS Forecasts}

This section contains the WN-FGLS robustness forecast results for forecast combinations. Table VIII, Panel A reports results for the combination of all predictor countries, the 5 largest net export countries, and the 5 largest net import countries at the 1-week forecast horizons. Using all countries, OOS predictability at the 1week horizon is small across all methods; forecasting by combinations are significant at the $10 \%$ level only and this is so for only three of the seven methods. There is no predictability if net-export country indices are used. However using net-import country indices, in five of the seven combination methods forecastability exists at the $7 \%$ level. The other two methods exhibit weak forecastability at the $11 \%$ level. In all cases, the MSFE is lower when import country indices are used compared to when export country indices are used. Overall, these results support the OLS results; predictability is most evident for net importers.

\section{[Table VIII about here.]}

Panel B of Table VIII provides the utility gain results using the WN-FGLS method. Utility gains are available for all combination forecast models, with the only two exceptions are the Median and $\mathrm{C}(3, \mathrm{~PB})$ methods using the five export country indices. Manipulation proof utility gain tests provide uniform gains. The important point of Panel B is that if only net-import country indices are used to forecast, the gains are typically double that of using all country indices and four or more times that of using only net-exporter country indices. Thus, consistent with Table IV, there is strong support that China's aggregate return is predictable using net-importer country indices.

Panel C of Table VIII provides the pre-WTO results using the OLS method. Recall that pre-WTO, individual models exhibited little predictablility. There were two explanations, either: (1) predictability 
is a post-WTO phenomenon or (2) the sample size is too small to measure the effect. Our combination method results help resolve this since combination methods are less susceptible to noise. In Panel C, we find predictability. Using all the data, all combination methods beat the benchmark and four of the seven combination method are significant at the $10 \%$ level of better. We also see strong support that net-importer countries are better predictors of net-exporter countries consistent with our results for the post-WTO period. Only one combination method significantly beats the benchmark when net-export country indices are used, while four beat the benchmark when net-import indices are used. Also, the reduction in the MSFE is larger in five of seven cases when net-import indices are used compared to using either all the indices or only net-export indices.

To summarize, our main findings that the Chinese market index can be forecast and that such forecasts are more accurate if only net-import country indices are used as predictors hold even after we control for heteroscedasticity, predictor endogeneity, and persistence. In addition, our results are not driven by the event of China joining the WTO.

\section{Conclusion}

There is an ongoing debate on whether aggregate market returns can be forecast. Most papers consider fundamental or macro predictors. The results have been mixed. Although China has attracted a lot of attention concerning cross-sectional predictability, to date, China's stock market return, a major emerging market in world trade, has few OOS predictability studies. Both prior OOS studies focus on standard fundamental and macro variables. Evidence on predictable relations between trade partners based on economic theory is lacking. We try to fill this gap.

Motivated by three results: (1) the US has strong OOS predictability for other industrialized nations, (2) China is a strongly commodity oriented economy and thus will face sticky revenues and fluctuating costs, and (3) economically-linked customer returns may provide valuable information for supplier nations, we propose two hypotheses. First, the US stock market return is useful in forecasting the Chinese stock market return. Second, we are able to discern between the sticky-price and economically-linked theories as they make opposite predictions concerning OOS predictability by countries that China are net exporters.

First, we find weak support for US OOS predictability of China. Thus, the results of Rapach, Strauss, 
and Zhou (2011) receive limited support in the case of China and thus may not hold for other emerging markets. Second, we find consistent support for the importance of the direction of trade links to China's economy. Net import countries, e.g., Australia, Brazil, and Malaysia, show strong OOS predictability for the aggregate Chinese equity market return. When forming combination forecasts, excluding net export countries improves the forecast gains both statistically and economically for all combination methods. Our empirical results are supportive of the sticky price theory. That is, due to producing manufactured exports where inflexible contracts determine prices, China's short term export revenue is sticky. However, price movements in raw materials, e.g., due to commodity speculation, must be absorbed in order to maintain output. Finally, our results provide evidence that noise is one of the major reasons combination methods achieve improvements over individual predictor models. That is, since export countries do not forecast in single predictor forecasts, including these in combination forecasts introduces noise. When these "noise" countries are removed, the significance of the combination forecast outperformance increases sharply. This is a novel result as research typically demonstrates that combinations over many predictor models usually outperform.

Our results suggest some interesting avenues for future research. The OOS predictability we document is short horizon in nature. Does short term OOS predictability exist in other emerging markets? Or is this due to institutional details of the Chinese market, e.g., Chinese A shares are mostly owned locally and the majority are held by the Chinese government. Will more open emerging markets exhibit different behavior? Thus, replicating our study for other markets, e.g., smaller emerging markets, more open markets, or markets with varying reliance on trade, would be interesting extensions. The existence of ETFs for China 'A' shares mean some benefits can be realized for foreign investors even though they cannot trade the underlying. 


\section{References}

Aiolfi, M. and Timmermann, A. 2006. Persistence in forecasting performance and conditional combination strategies. Journal of Econometrics, 135(1-2): 31-53.

Aulakh, P. S., Kotabe, M., and Teegen, H., 2000. Export strategies and performance of firms from emerging economies: Evidence from Brazil, Chile, and Mexico. Academy of Management Journal, 43(3): 342-361.

Campbell, J. and Thompson, S. 2008. Predicting excess stock returns out of sample: Can anything beat the historical average? Review of Financial Studies, 21(4): 1509-1531.

Campbell, J. Y. and Viceira, L. M. 2002, Strategic Asset Allocation, Clarendon Lectures in Economics, Oxford University Press.

Chan, K. C., Fung, H. G., and Thapa, S., 2007. China financial research: A review and synthesis. International Review of Economics and Finance, 16(3): 416-428.

Chen, X., Kim, K. A., Yao, T., and Yu, T., 2010. On the predictability of Chinese stock returns. Pacific-Basin Finance Journal, 18: 403-425.

Clark, T. E. and West, K. D. 2007. Approximately normal tests for equal predictive accuracy in nested models. Journal of Econometrics, 138(1): 291-311.

Cohen, L. and Frazzini, A. 2008. Economic links and predictable returns. Journal of Finance, 63(4): 19772011.

Goetzmann, W., Ingersoll, J, Speigel, M., and Welch, I. 2007. Portfolio performance manipulation and manipulation-proof performance measures. Review of Financial Studies, 20(5): 1503-1546.

Goh, J. C., Jiang, F., Tu, J., and Wang, Y., 2013. Can US economic variables predict the Chinese stock market? Pacific-Basin Finance Journal, 22: 69-87.

Harvey, D. I., Leybourne, S. J., Newbold, P. 1998. Tests for forecast encompassing. Journal of Business and Economic Statistics 16(2): 254-259.

Hsiao, C., Ching, H. S., and Wan, S. K. 2012. A panel data approach for program evaluation: Measuring the benefits of political and economic integration of Hong Kong with mainland China. Journal of Applied Econometrics, 27(5): 705-740.

Jordan, S. J. and Vivian, A. J. 2012. Forecasting stock returns internationally: Can fundamental-price models beat the historical average? IFABS 2011 Conference Paper, Rome.

Jordan, S. J., Vivian, A. J., and Wohar M. E. 2012. Forecasting Asian market returns: Bagging or combining? 32nd Annual International Symposium on Forecasting Paper, Boston.

Lee, C. F. and O. M. Rui 2000. Does trading volume contain information to predict stock returns? Evidence from China's stock markets. Review of Quantitative Finance and Accounting, 14(3): 341-360.

Lewellen, J., 2004. Predicting returns with financial ratios. Journal of Financial Economics, 74(2): 209235.

Li, J. J., Zhou, K. Z., and Shao, A. T., 2009. Competitive position, managerial ties, and profitability of foreign firms in China: an interactive perspective. Journal of International Business Studies, 40(2): 339352.

Rapach D. E., Strauss J. K., and Zhou, G. F. 2010. Out-of-sample equity premium prediction: Combination forecasts and links to the real economy. Review of Financial Studies, 23(2): 821-862.

Rapach D. E., Strauss J. K., and Zhou, G. F. 2011. International stock return predictability: What is the role of the United States? SSRN Working Paper No. 1508484.

Sheng, L., 2013. Did China diversify its foreign reserves? Journal of Applied Econometrics, 28(1): 102- 
125.

Stambaugh, R.F., 1999. Predictive regressions. Journal of Financial Economics, 54(3): 375-421.

Stock, J. and Watson, M. 2004. Combination forecasts of output growth in a seven-country data set. Journal of Forecasting, 23(6): 405-430.

Szamosszegi, A. and Cole, K., 2011. An analysis of state-owned enterprises and state capitalism in China. U.S.-China Economic and Security Review Commission, http://www.uscc.gov/researchpapers/2011/ 10_26_11_CapitalTradeSOEStudy.pdf

The Economist, 2011. Becoming number one: China's economy could overtake America's within a decade. http://www.economist.com/node/21528987.

Wang, F. and Xu, Y., 2004. What determines Chinese stock returns? Financial Analysts Journal, 60(6): $65-77$.

Westerlund, J. and Narayan, P. K., 2011. Testing the predictability in heteroscedastic stock returns. Unpublished Manuscript.

Westerlund, J. and Narayan, P., 2012. Does the choice of estimator matter when forecasting returns? Journal of Banking and Finance, 36(9): 2632-2640. 
Table I: Descriptive Statistics

This table provides descriptive statistics for the log stock return for the country indices used in this study. Mean is the sample average of the log stock return. SD is the standard deviation, Min is the minimum value and Max is the maximum value. AU is Australia, BR is Brazil, BD is Germany, CH is China, IN is India, JP is Japan, NL is Netherlands, MY is Malaysia, SG is Singapore, KO is South Korea, TW is Taiwan, TH is Thailand, UK is the United Kingdom, and US is the United States. Using weekly data, our sample period is from week 1 of 1995 to week 52 of 2011.

\begin{tabular}{|cc|ccccccc|}
\cline { 3 - 9 } \multicolumn{1}{c|}{} & & CH & AU & BR & BD & IN & JP & NL \\
\hline RET & Mean & 0.0017 & 0.0017 & 0.0030 & 0.0011 & 0.0020 & -0.0005 & 0.0012 \\
& SD & 0.0400 & 0.0208 & 0.0375 & 0.0290 & 0.0411 & 0.0287 & 0.0296 \\
& Min & 0.2138 & 0.1188 & 0.2185 & 0.1188 & 0.1574 & 0.1497 & 0.1987 \\
& Max & -0.2351 & -0.1085 & -0.1860 & -0.1684 & -0.2426 & -0.2006 & -0.1578 \\
\hline
\end{tabular}

\begin{tabular}{|cc|ccccccc|}
\cline { 3 - 9 } \multicolumn{1}{c|}{} & MY & SG & KO & TW & TH & UK & US \\
\hline \multirow{4}{*}{ RET } & Mean & 0.0011 & 0.0009 & 0.0015 & 0.0006 & 0.0005 & 0.0014 & 0.0016 \\
& SD & 0.0340 & 0.0295 & 0.0437 & 0.0364 & 0.0457 & 0.0247 & 0.0256 \\
& Min & 0.2767 & 0.1184 & 0.1868 & 0.1623 & 0.3050 & 0.1693 & 0.1234 \\
& Max & -0.1956 & -0.1427 & -0.1872 & -0.1161 & -0.2060 & -0.1184 & -0.1633 \\
\hline
\end{tabular}




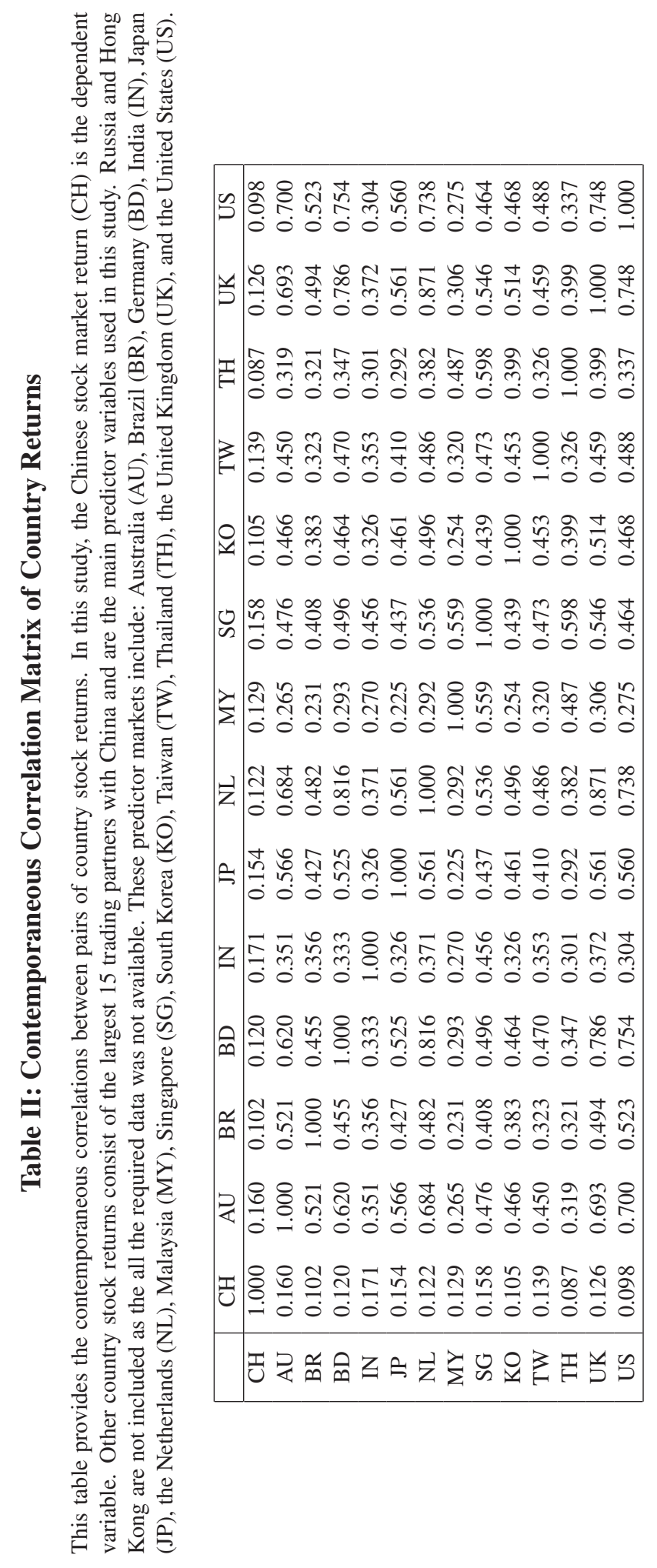




\section{Table III: Forecasting Chinese Market Returns - Lagged Country Returns Against AR(p) Benchmark}

The first column gives the stock return used in the ARDL model to forecast the Chinese stock market return. The first row gives the horizon over which the Chinese equity market return is forecast. $\mathrm{Im} / \mathrm{Ex}$ indicates if China is a net importer (I) or a net exporter (E) to that specific country. AR(MSFE) reports the mean-squared forecast error for the benchmark AR(p) model. The MSFE columns report the ratio of the mean-squared forecast errors for each ARDL model to the mean-squared forecast error of the AR(p) model. The CW columns report the Clark and West (CW, 2007) MSPE adjusted test statistic, which is a one-sided test. The p(CW) columns reports the p-value for the Clark and West (2007) MSPE adjusted test statistic. Statistical significance whether the mean-squared forecast error from the individual model is smaller than the AR(p) model at the 5\% (10\%) or better is represented by ** $(*)$. Each ARDL model includes lagged dependent variable and the lagged returns for the country given in column 1 . Using weekly data, we forecast returns from week 2 of 2005 to week 52 of 2011 .

\begin{tabular}{|c|c|c|c|c|c|c|c|c|c|c|}
\hline & & \multicolumn{3}{|c|}{ ONE WEEK } & \multicolumn{3}{|c|}{ TWO WEEKS } & \multicolumn{3}{|c|}{ FOUR WEEKS } \\
\hline & $\mathrm{Im} / \mathrm{Ex}$ & MSFE & CW & $\mathrm{p}(\mathrm{CW})$ & MSFE & CW & $\mathrm{p}(\mathrm{CW})$ & MSFE & $\mathrm{CW}$ & $\mathrm{p}(\mathrm{CW})$ \\
\hline AR(MSFE) & & 0.0016 & & & 0.0008 & & & 0.0005 & & \\
\hline $\mathrm{AU}$ & I & $0.988^{* * *}$ & 1.723 & 0.04 & 0.995 & 1.088 & 0.14 & 0.999 & 0.585 & 0.28 \\
\hline BR & I & $0.985^{* *}$ & 2.303 & 0.01 & 0.997 & 0.726 & 0.23 & 0.995 & 1.152 & 0.12 \\
\hline $\mathrm{BD}$ & I & $0.994 *$ & 1.332 & 0.09 & 0.998 & 0.869 & 0.19 & 1.000 & 0.594 & 0.28 \\
\hline IN & E & 0.999 & 0.525 & 0.30 & 1.001 & 0.113 & 0.46 & 1.000 & 0.587 & 0.28 \\
\hline JP & I & 1.000 & 0.330 & 0.37 & 1.002 & -0.322 & 0.63 & 0.999 & 0.404 & 0.34 \\
\hline NL & $\mathrm{E}$ & 0.994 & 1.232 & 0.11 & 0.998 & 0.833 & 0.20 & 0.998 & 0.990 & 0.16 \\
\hline MY & I & $0.992 * *$ & 1.821 & 0.03 & 0.999 & 0.391 & 0.35 & 0.996 & 1.256 & 0.10 \\
\hline SG & $\mathrm{E}$ & 0.998 & 0.800 & 0.21 & 1.001 & -0.024 & 0.51 & 0.998 & 0.802 & 0.21 \\
\hline SK & I & 1.001 & -0.109 & 0.54 & 0.997 & 0.881 & 0.19 & 1.000 & 0.348 & 0.36 \\
\hline TW & I & $0.990 *$ & 1.561 & 0.06 & 0.995 & 1.113 & 0.13 & 0.998 & 0.802 & 0.21 \\
\hline $\mathrm{TH}$ & I & 1.003 & -1.676 & 0.95 & 1.000 & 0.042 & 0.48 & 1.000 & 0.431 & 0.33 \\
\hline UK & $\mathrm{E}$ & 0.999 & 0.692 & 0.24 & 1.000 & 0.570 & 0.28 & 1.001 & 0.508 & 0.31 \\
\hline US & E & $0.993 *$ & 1.417 & 0.08 & 1.006 & -0.079 & 0.53 & 0.999 & 0.702 & 0.24 \\
\hline
\end{tabular}


Table IV: Forecast Combinations Against AR(p) Benchmark

The first column gives the forecast combination method used to forecast the Chinese stock market return. The first row gives horizon over which the Chinese equity market return is forecast. AR(MSFE) reports the mean-squared forecast error for the benchmark AR(p) model. MSFE columns report the ratio of the mean-squared forecast errors for each ARDL models to the mean-squared forecast error of the AR(p) model. CW columns report the Clark and West (CW, 2007) MSPE adjusted test statistic, which is a onesided test. $\mathrm{p}(\mathrm{CW})$ columns reports the p-value for the Clark and West (2007) MSPE adjusted test statistic; statistical significance at the 5\% (10\%) or better is represented by $* *(*)$. Mean, Median and Trimmed (Mean) are combinations based on measures of central tendency. DMSFE(1) and DMSFE( 0.9$)$ are combinations based on the weighted past forecast error. $\mathrm{C}(2, \mathrm{~PB})$ and $\mathrm{C}(3, \mathrm{~PB})$ are combinations based on cluster methods. $\mathrm{PC}(\mathrm{C}, 3 \mathrm{~B})$ is a combination based on principal components. In Panel B (C) combinations are based on a subset of 5 net export (net import) countries. 5 EXPORTERS (5 IMPORTERS) are the five countries which China has the highest net imports (net exports) from.

Panel A: ALL COUNTRIES (OOS FORECAST)

\begin{tabular}{|c|ccc|cccc|ccc|}
\hline & \multicolumn{3}{|c|}{ ONE WEEK } & \multicolumn{3}{c|}{ TWO WEEKS } & \multicolumn{3}{c|}{ FOUR WEEKS } \\
\cline { 2 - 10 } & MSFE & CW & $\mathrm{p}(\mathrm{CW})$ & MSFE & CW & $\mathrm{p}(\mathrm{CW})$ & MSFE & CW & $\mathrm{p}(\mathrm{CW})$ \\
\hline AR (MSFE) & 0.0016 & & & 0.0008 & & & 0.0005 & & \\
Mean & $0.993^{*}$ & 1.458 & 0.07 & 0.997 & 0.775 & 0.22 & 0.997 & 0.884 & 0.19 \\
Median & $0.993^{*}$ & 1.383 & 0.08 & 0.996 & 1.060 & 0.14 & 0.998 & 0.877 & 0.19 \\
Trimmed & $0.993^{*}$ & 1.365 & 0.09 & 0.998 & 0.712 & 0.24 & 0.997 & 0.882 & 0.19 \\
DMSFE(1) & $0.993^{*}$ & 1.456 & 0.07 & 0.997 & 0.773 & 0.22 & 0.997 & 0.881 & 0.19 \\
DMSFE(0.9) & $0.993^{*}$ & 1.452 & 0.07 & 0.997 & 0.768 & 0.22 & 0.997 & 0.880 & 0.19 \\
C(2,PB) & $0.991^{*}$ & 1.507 & 0.07 & 0.999 & 0.341 & 0.37 & 0.999 & 0.626 & 0.27 \\
C(3,PB) & $0.990^{*}$ & 1.541 & 0.06 & 1.003 & 0.109 & 0.46 & 0.999 & 0.645 & 0.26 \\
\hline
\end{tabular}

Panel B: COMBINATIONS - 5 EXPORTERS (OOS FORECAST)

\begin{tabular}{|c|ccc|cccc|ccc|}
\hline & \multicolumn{3}{|c|}{ ONE WEEK } & \multicolumn{3}{c|}{ TWO WEEKS } & \multicolumn{3}{c|}{ FOUR WEEKS } \\
\cline { 2 - 9 } & MSFE & CW & $\mathrm{p}(\mathrm{CW})$ & MSFE & CW & $\mathrm{p}(\mathrm{CW})$ & MSFE & CW & $\mathrm{p}(\mathrm{CW})$ \\
\hline AR (MSFE) & 0.0016 & & & 0.0008 & & & 0.0005 & & \\
Mean & 0.994 & 1.149 & 0.13 & 1.000 & 0.477 & 0.32 & 0.997 & 0.833 & 0.20 \\
Median & 0.998 & 0.767 & 0.22 & 1.003 & 0.072 & 0.47 & 1.001 & 0.364 & 0.36 \\
Trimmed & 0.996 & 0.992 & 0.16 & 0.999 & 0.559 & 0.29 & 0.998 & 0.759 & 0.22 \\
DMSFE(1) & 0.994 & 1.148 & 0.13 & 1.000 & 0.476 & 0.32 & 0.997 & 0.831 & 0.20 \\
DMSFE(0.9) & 0.994 & 1.143 & 0.13 & 1.000 & 0.479 & 0.32 & 0.997 & 0.829 & 0.20 \\
C(2,PB) & 0.993 & 1.196 & 0.12 & 1.002 & 0.244 & 0.40 & 0.999 & 0.730 & 0.23 \\
C(3,PB) & 0.990 & 1.465 & 0.07 & 1.002 & 0.385 & 0.35 & 1.000 & 0.653 & 0.26 \\
\hline
\end{tabular}

Panel C: COMBINATIONS - 5 IMPORTERS (OOS FORECAST)

\begin{tabular}{|c|ccc|ccc|ccc|}
\hline & \multicolumn{3}{|c|}{ ONE WEEK } & \multicolumn{3}{c|}{ TWO WEEKS } & \multicolumn{3}{c|}{ FOUR WEEKS } \\
\cline { 2 - 10 } & MSFE & CW & p(CW) & MSFE & CW & p(CW) & MSFE & CW & p(CW) \\
\hline AR (MSFE) & 0.0016 & & & 0.0008 & & & 0.0005 & & \\
Mean & $0.991^{* *}$ & 1.680 & 0.05 & 0.996 & 1.021 & 0.15 & 0.997 & 0.850 & 0.20 \\
Median & $0.993^{*}$ & 1.410 & 0.08 & 0.995 & 1.041 & 0.15 & 0.997 & 0.899 & 0.18 \\
Trimmed & $0.992^{*}$ & 1.551 & 0.06 & 0.996 & 0.980 & 0.16 & 0.996 & 1.030 & 0.15 \\
DMSFE(1) & $0.991^{* *}$ & 1.679 & 0.05 & 0.996 & 1.018 & 0.15 & 0.997 & 0.849 & 0.20 \\
DMSFE(0.9) & $0.991^{* *}$ & 1.681 & 0.05 & 0.996 & 1.005 & 0.16 & 0.997 & 0.848 & 0.20 \\
C(2,PB) & $0.990^{* *}$ & 1.661 & 0.05 & 0.999 & 0.524 & 0.30 & 1.000 & 0.400 & 0.34 \\
C(3,PB) & $0.986^{* *}$ & 2.038 & 0.02 & 1.004 & 0.068 & 0.47 & 1.000 & 0.564 & 0.29 \\
\hline
\end{tabular}


Table V: Encompassing Test 1-Week OOS Forecast Using Country Returns

This table reports results of forecast encompassing tests on pairs of the country returns. The results are calculated for the MHLN test is the Harvey, Leybourne and Newbold (1998) forecast encompassing test. The null hypothesis is that the country return in Column has a weight of zero when combined with the country return in Row. A p-value of less than 0.05 indicates that the weight on the country return in Column is statistically different from 0 at the $5 \%$ level of significance or better. For example for Australia (Column) and India (Row) the p-value of 0.04 indicates that we can reject the null hypothesis that the forecast based on Australia has a weight of zero when combined with the forecast based on India. Thus, the Australian forecast is not encompassed by the Indian forecast, i.e., the Australian forecast adds new information over and above that contained in the Indian forecast.

\begin{tabular}{|c|c|c|c|c|c|c|c|c|c|c|c|c|c|c|}
\hline & \multicolumn{13}{|c|}{ Column } \\
\hline & & $\mathrm{AU}$ & $\overline{B R}$ & $\mathrm{BD}$ & IN & JP & $\mathrm{NL}$ & MY & SG & $\mathrm{KO}$ & TW & TH & UK & US \\
\hline \multirow{13}{*}{ Row } & $\mathrm{AU}$ & & 0.22 & 0.46 & 0.62 & 0.79 & 0.57 & 0.37 & 0.59 & 0.65 & 0.32 & 0.62 & 0.89 & 0.56 \\
\hline & BR & 0.41 & & 0.62 & 0.92 & 0.97 & 0.62 & 0.69 & 0.92 & 0.96 & 0.43 & 0.93 & 0.90 & 0.64 \\
\hline & BD & 0.08 & $0.03^{*}$ & & 0.46 & 0.59 & 0.23 & 0.20 & 0.43 & 0.53 & 0.14 & 0.54 & 0.58 & 0.24 \\
\hline & IN & $0.04 *$ & $0.01 *$ & 0.09 & & 0.45 & 0.13 & 0.06 & 0.33 & 0.51 & 0.06 & 0.59 & 0.31 & 0.09 \\
\hline & $\mathrm{JP}$ & $0.02 *$ & $0.00 *$ & $0.05^{*}$ & 0.28 & & 0.09 & $0.05^{*}$ & 0.25 & 0.41 & $0.05^{*}$ & 0.49 & 0.27 & 0.07 \\
\hline & NL & 0.09 & 0.10 & 0.23 & 0.40 & 0.50 & & 0.21 & 0.38 & 0.43 & 0.16 & 0.41 & 0.72 & 0.25 \\
\hline & MY & 0.13 & 0.08 & 0.29 & 0.84 & 0.82 & 0.29 & & 0.90 & 0.95 & 0.17 & 0.95 & 0.59 & 0.23 \\
\hline & SG & 0.06 & $0.01 *$ & 0.12 & 0.42 & 0.51 & 0.15 & $0.04 *$ & & 0.78 & 0.08 & 0.85 & 0.34 & 0.11 \\
\hline & $\mathrm{KO}$ & $0.04 *$ & $0.00 *$ & 0.07 & 0.27 & 0.36 & 0.11 & $0.02 *$ & 0.12 & & $0.05^{*}$ & 0.72 & 0.25 & 0.07 \\
\hline & TW & 0.19 & 0.16 & 0.33 & 0.56 & 0.62 & 0.36 & 0.29 & 0.49 & 0.56 & & 0.54 & 0.62 & 0.34 \\
\hline & $\mathrm{TH}$ & $0.03 *$ & $0.00^{*}$ & $0.05^{*}$ & 0.17 & 0.23 & 0.08 & $0.01 *$ & $0.05^{*}$ & 0.17 & $0.04 *$ & & 0.17 & $0.05 *$ \\
\hline & UK & $0.02 *$ & $0.03^{*}$ & 0.09 & 0.27 & 0.36 & 0.11 & 0.10 & 0.27 & 0.35 & 0.06 & 0.37 & & 0.11 \\
\hline & US & 0.09 & 0.07 & 0.30 & 0.40 & 0.57 & 0.29 & 0.20 & 0.39 & 0.45 & 0.18 & 0.44 & 0.61 & \\
\hline
\end{tabular}




\section{Table VI: Portfolio Allocation Results}

This table reports the economic significance of regression forecasts. The utility gain (GAIN) and the GISW (Goetzmann et al., 2007) performance gain between the model in column 1 and the AR(p) benchmark. Utility gains are reported as percentage points and are annualized by multiplying weekly values by 52 . Utility gains are calculated for an investor with mean-variance preferences under assumptions of a relative risk aversion coefficient of 3 and limiting the weight in the risky asset to be no less than 0 and no more than 1.5 (as in Campbell and Thompson, 2008). We forecast the return and use the current market risk-free rate to calculate the excess return.

Mean, Median and Trimmed (Mean) are combinations based on measures of central tendency. DMSFE(1) and DMSFE(0.9) are combinations based on the weighted past forecast error. $\mathrm{C}(2, \mathrm{~PB})$ and $\mathrm{C}(3, \mathrm{~PB})$ are combinations based on cluster methods.

Panel A provides individual country results where the countries are separated into countries China is a net importer (IMPORTERS) and a net exporter (EXPORTERS). Panel B provides combination forecast results. Panel B consists of three sections: ALL, IMPORTERS, and EXPORTERS. IMPORTERS (EXPORTERS) are the five countries for which China has the highest net imports (net exports) from.

Panel A: Portfolio Allocation - Country Returns

\begin{tabular}{|ccc|ccc|}
\hline Importers & GAIN & GISW & Exporters & GAIN & GISW \\
\hline AU & 9.30 & 11.84 & IN & 3.26 & 5.19 \\
BR & 8.07 & 10.31 & NL & 3.03 & 6.87 \\
BD & 6.66 & 9.92 & SG & 0.31 & 0.84 \\
JP & -1.09 & 0.56 & UK & 2.99 & 5.67 \\
MY & 3.40 & 5.56 & US & 6.80 & 10.40 \\
KO & -2.24 & -2.03 & & & \\
TW & 9.37 & 13.77 & & & \\
TH & -3.70 & -3.62 & & & \\
\hline
\end{tabular}

Panel B: Import/Export Portfolio Allocation - Forecast Combinations

\begin{tabular}{|c|cc|cc|cc|}
\hline \multirow{2}{*}{} & \multicolumn{2}{|c|}{ ALL } & \multicolumn{2}{c|}{ IMPORTERS } & \multicolumn{2}{c|}{ EXPORTERS } \\
\cline { 2 - 7 } & GAIN & GISW & GAIN & GISW & GAIN & GISW \\
\hline Mean & 4.87 & 6.55 & 6.41 & 8.23 & 3.97 & 6.03 \\
Median & 4.43 & 6.12 & 3.86 & 5.17 & 2.59 & 5.03 \\
Trimmed & 4.41 & 6.03 & 4.26 & 5.76 & 3.58 & 5.77 \\
DMSFE(1) & 4.88 & 6.56 & 6.42 & 8.24 & 3.98 & 6.04 \\
DMSFE(0.9) & 4.93 & 6.61 & 6.49 & 8.31 & 3.97 & 6.03 \\
C(2,PB) & 7.11 & 9.61 & 9.22 & 11.91 & 5.35 & 8.12 \\
C(3,PB) & 8.98 & 12.13 & 10.94 & 14.09 & 6.60 & 9.79 \\
\hline
\end{tabular}


Table VII: Robustness - Forecasting Chinese Market Returns - Lagged Country Returns Against AR(p) Benchmark

The first column gives the stock return used to forecast the Chinese stock market return. The first row gives the subset of market indices used to forecast the Chinese equity market return. AR(MSFE) reports the mean-squared forecast error for the benchmark $\mathrm{AR}(\mathrm{p})$ model. MSFE columns report the ratio of the mean-squared forecast errors for each model to the mean-squared forecast error of the AR(p) model. CW columns report the Clark and West (CW, 2007) MSPE adjusted test statistic, which is a one-sided test. p(CW) columns reports the p-value for the Clark and West (2007) MSPE adjusted test statistic. "Utility Gains" reports the gain in utility to a mean-variance optimizer, while GISW provides the manipulation proof utility gain. Statistical significance whether the mean-squared forecast error from the individual model is smaller than the AR(p) model at the 5\% (10\%) or better is represented by $* *(*)$. Each model includes lagged dependent variable and the lagged returns for the country given in column 1 . Using weekly data, we forecast returns from week 2 of 2005 to week 52 of 2011.

Panel A provides results for the whole sample period using the Westerlund and Narayan (2012) Feasible Generalized Least Squares (WN-FGLS) model. This model adjusts for heteroscedasticity, predictor persistence, and omitted-variable bias. Panel B provides results for the pre-WTO period using the standard OLS method for the ARDL model.

\begin{tabular}{|c|c|c|c|c|c|c|c|c|}
\hline & \multicolumn{5}{|c|}{ Panel A: All Data } & \multirow{2}{*}{\multicolumn{3}{|c|}{$\begin{array}{c}\text { Panel B: Pre } 2002 \text { Sample } \\
\text { OLS 1-week OOS FORECAST }\end{array}$}} \\
\hline & \multicolumn{3}{|c|}{ FGLS 1-week OOS FORECAST } & \multicolumn{2}{|c|}{ FGLS Utility Gains } & & & \\
\hline & MSFE & $\mathrm{CW}$ & $\mathrm{p}(\mathrm{CW})$ & Utility Gain & GISW & MSFE & CW & $\mathrm{p}(\mathrm{CW})$ \\
\hline AR (MSFE) & 0.0016 & & & & & 0.0016 & & \\
\hline $\mathrm{AU}$ & 0.991 & 2.007 & 0.02 & 8.73 & 15.74 & 1.000 & 0.138 & 0.44 \\
\hline $\mathrm{BR}$ & 0.998 & 0.916 & 0.18 & 0.61 & 2.88 & 1.002 & -0.114 & 0.55 \\
\hline $\mathrm{BD}$ & 1.004 & 0.755 & 0.23 & 0.90 & 5.94 & 1.001 & 0.718 & 0.24 \\
\hline IN & 1.005 & 0.891 & 0.19 & -0.35 & 6.68 & 1.005 & -0.186 & 0.57 \\
\hline JP & 1.006 & 0.779 & 0.22 & -3.18 & 2.78 & 1.002 & -0.499 & 0.69 \\
\hline NL & 1.001 & 1.080 & 0.14 & -3.13 & 2.58 & 1.004 & 0.616 & 0.27 \\
\hline MY & 0.990 & 1.614 & 0.05 & 2.82 & 7.56 & 1.007 & -0.280 & 0.61 \\
\hline SG & 0.995 & 1.379 & 0.08 & 3.81 & 8.12 & 1.004 & -0.056 & 0.52 \\
\hline SK & 0.999 & 0.641 & 0.26 & -1.04 & 1.03 & 1.004 & -1.452 & 0.93 \\
\hline TW & 1.001 & 1.033 & 0.15 & 1.55 & 7.45 & 1.011 & 1.743 & 0.04 \\
\hline $\mathrm{TH}$ & 1.001 & 0.241 & 0.40 & -1.57 & 0.18 & 1.007 & -0.081 & 0.53 \\
\hline UK & 1.007 & 0.657 & 0.26 & -1.75 & 3.11 & 1.004 & 0.633 & 0.26 \\
\hline US & 1.006 & 0.779 & 0.22 & -4.77 & 0.24 & 0.995 & 1.175 & 0.12 \\
\hline
\end{tabular}




\section{Table VIII: Robustness - Forecast Combinations Against AR(p) Benchmark}

The first column gives the forecast combination method used to forecast the Chinese stock market return. The first row gives subset of market predictor forecasts used to form the combination foreacst of the Chinese equity market return. AR(MSFE) reports the mean-squared forecast error for the benchmark AR(p) model. MSFE columns report the ratio of the mean-squared forecast errors for each ARDL models to the mean-squared forecast error of the AR(p) model. CW columns report the Clark and West (CW, 2007) MSPE adjusted test statistic, which is a one-sided test. p(CW) columns reports the p-value for the Clark and West (2007) MSPE adjusted test statistic; statistical significance at the 5\% (10\%) or better is represented by ** (*). Mean, Median and Trimmed (Mean) are combinations based on measures of central tendency. DMSFE(1) and DMSFE(0.9) are combinations based on the weighted past forecast error. $\mathrm{C}(2, \mathrm{~PB})$ and $\mathrm{C}(3, \mathrm{~PB})$ are combinations based on cluster methods. $\mathrm{PC}(\mathrm{C}, 3 \mathrm{~B})$ is a combination based on principal components. In Panel B (C) combinations are based on a subset of 5 net export (net import) countries. 5 EXPORTERS (5 IMPORTERS) are the five countries which China has the highest net imports (net exports) from.

Panel A provides results for the Westerlund and Narayan (2012) Feasible Generalized Least Squares (WN-FGLS) model. This model adjusts for heteroscedasticity, predictor persistence, and omitted-variable bias. Panel B provides the WN-FGLS results for the utility gains tests. Both standard utility gain and manipulation proof (GISW) utility gains are provided. Panel C provides results for the pre-WTO period using the standard OLS method for the ARDL model.

Panel A: FGLS Combination 1-week OOS Forecast (MSFE)

\begin{tabular}{|c|ccc|cccc|ccc|}
\hline & \multicolumn{3}{|c|}{ All Countries } & \multicolumn{3}{c|}{ 5 EXPORTERS } & \multicolumn{3}{c|}{ 5 IMPORTERS } \\
\cline { 2 - 10 } & MSFE & CW & $\mathrm{p}(\mathrm{CW})$ & MSFE & CW & $\mathrm{p}(\mathrm{CW})$ & MSFE & CW & $\mathrm{p}(\mathrm{CW})$ \\
\hline AR (MSFE) & 0.0016 & & & 0.0016 & & & 0.0016 & & \\
Mean & 0.994 & 1.279 & 0.10 & 0.999 & 1.051 & 0.15 & 0.992 & 1.488 & 0.07 \\
Median & 0.996 & 1.094 & 0.14 & 1.004 & 0.713 & 0.24 & 0.995 & 1.238 & 0.11 \\
Trimmed & 0.995 & 1.246 & 0.11 & 1.001 & 0.898 & 0.18 & 0.992 & 1.450 & 0.07 \\
DMSFE(1) & 0.994 & 1.278 & 0.10 & 0.999 & 1.050 & 0.15 & 0.992 & 1.487 & 0.07 \\
DMSFE(0.9) & 0.994 & 1.281 & 0.10 & 0.999 & 1.047 & 0.15 & 0.992 & 1.511 & 0.07 \\
C(2,PB) & 0.997 & 1.064 & 0.14 & 1.000 & 1.012 & 0.16 & 0.994 & 1.248 & 0.11 \\
C(3,PB) & 0.999 & 1.011 & 0.16 & 1.000 & 0.984 & 0.16 & 0.993 & 1.484 & 0.07 \\
\hline
\end{tabular}

Panel B: FGLS Combination 1-week OOS Forecast (Utility Gains)

\begin{tabular}{|c|cc|cc|cc|}
\hline & \multicolumn{3}{|c|}{ All Countries } & \multicolumn{2}{c|}{ 5 EXPORTERS } & \multicolumn{2}{c|}{ 5 IMPORTERS } \\
\cline { 2 - 7 } & Utility & GISW & Utility & GISW & Utility & GISW \\
\hline Mean & 2.78 & 6.79 & 0.86 & 5.65 & 4.16 & 8.24 \\
Median & 1.23 & 4.97 & -1.80 & 2.93 & 3.93 & 7.43 \\
Trimmed & 2.82 & 6.85 & 0.26 & 5.10 & 4.24 & 7.96 \\
DMSFE(1) & 2.78 & 6.79 & 0.86 & 5.65 & 4.15 & 8.23 \\
DMSFE(0.9) & 2.77 & 6.77 & 0.78 & 5.55 & 4.20 & 8.27 \\
C(2,PB) & 1.64 & 5.96 & -0.33 & 4.64 & 2.17 & 6.63 \\
\hline
\end{tabular}

Panel C: PRE 2002 SAMPLE - OLS Cobintion 1-week forecast

\begin{tabular}{|c|ccc|cccc|ccc|}
\hline & \multicolumn{3}{|c|}{ All Countries } & \multicolumn{3}{c|}{ 5 EXPORTERS } & \multicolumn{3}{c|}{ 5 IMPORTERS } \\
\cline { 2 - 10 } & MSFE & CW & $\mathrm{p}(\mathrm{CW})$ & MSFE & CW & $\mathrm{p}(\mathrm{CW})$ & MSFE & CW & $\mathrm{p}(\mathrm{CW})$ \\
\hline AR (MSFE) & 0.0011 & & & 0.0011 & & & 0.0011 & & \\
Mean & 0.992 & 1.454 & 0.07 & 0.995 & 0.876 & 0.19 & 0.988 & 1.533 & 0.06 \\
Median & 0.998 & 0.550 & 0.29 & 0.994 & 0.999 & 0.16 & 0.998 & 0.862 & 0.19 \\
Trimmed & 0.995 & 1.121 & 0.13 & 0.994 & 0.975 & 0.16 & 0.998 & 0.674 & 0.25 \\
DMSFE(1) & 0.992 & 1.473 & 0.07 & 0.995 & 0.875 & 0.19 & 0.988 & 1.540 & 0.06 \\
DMSFE(0.9) & 0.993 & 1.340 & 0.09 & 0.996 & 0.830 & 0.20 & 0.989 & 1.449 & 0.07 \\
C(2,PB) & 0.995 & 1.032 & 0.15 & 0.992 & 1.443 & 0.07 & 0.992 & 1.131 & 0.13 \\
C(3,PB) & 0.990 & 1.300 & 0.10 & 0.998 & 0.462 & 0.32 & 0.987 & 1.409 & 0.08 \\
\hline
\end{tabular}

